\title{
Chimpanzee Interactions with Nonhuman Species in an Anthropogenic Habitat
}

Kimberley J. Hockings ${ }^{1,2,3}$, Tatyana Humle ${ }^{4}$, Susana Carvalho ${ }^{5,6}$, Tetsuro Matsuzawa ${ }^{7}$

${ }^{1}$ Departmento de Antropologia, Faculdade de Ciências Sociais e Humanas, Universidade Nova de Lisboa,Portugal

${ }^{2}$ Centre for Research in Anthropology (CRIA), Portugal

${ }^{3}$ Anthropology Centre for Conservation, Environment and Development, Oxford Brookes

University, Oxford, United Kingdom

${ }^{4}$ School of Anthropology and Conservation, University of Kent, Canterbury, United Kingdom

${ }^{5}$ Department of Archaeology and Anthropology, Division of Biological Anthropology, Leverhulme Centre for Human Evolutionary Studies, University of Cambridge, Cambridge, United Kingdom

${ }^{6}$ Research Centre for Anthropology and Health (CIAS), Coimbra, Portugal

${ }^{7}$ Primate Research Institute, Kyoto University, Japan

\section{Correspondence}

Kimberley J. Hockings

Departamento de Antropologia

Universidade Nova de Lisboa

Av. Berna, 26-C

1069-061 Lisboa

Portugal

Corresponding author's email address: hock@fcsh.unl.pt 


\section{Summary}

Interactions between wildlife species are numerous and diverse, ranging from commensalism to predation. Information on cross-species interactions in anthropogenic habitats are rare but can serve to improve our understanding of animal behavioural and ecological flexibility in response to human-induced changes. Here we report direct observations of interactions between chimpanzees (Pan troglodytes verus) and wild and domesticated species in a forest-farm mosaic at Bossou, Guinea, recorded between 1997 and 2009. The low diversity and abundance of wildlife, in particular typical chimpanzee prey species, are reflected in both the low interaction rates (one interaction per 400 observation hours) and the low number of species with which chimpanzees interacted (nine species, mostly mammals, but also birds and reptiles). Chimpanzees generally chose either to make direct physical contact with a species or not; interactions that involved direct contact lasted longer than non-contacts. Interactions with mammals showed the greatest diversity in nature and duration. Adults most often consumed a captured animal, while immatures most often engaged in playful behaviours with other species. Immatures also exhibited distinctive accompanying behaviours whereas adults rarely did so. Species-specific behaviours that depend on the age-class of the interactant are consistent with the idea that chimpanzees categorise different animals. We anticipate that chimpanzee interactions with sympatric species inhabiting humanised habitats will change over time to include more domesticated species. Conservation management strategies should anticipate behavioural flexibility in response to changing landscapes. 


\section{Introduction}

Wildlife species interact with each other in numerous, complex ways. Cross-species interactions can be persistent and prolonged or brief and rare, ranging from commensalism to predation. Although certain cross-species interactions in mammals, such as predation or anti-predatory associations between species for defensive purposes, are well-reported (Endler, 1991), most other forms of interaction go unreported or remain anecdotal, including instances such as cross-species play or alloparenting in the wild. Examples of such cases include a female Japanese macaque (Macaca fuscata) riding on the back of sympatric deer (Cervus nippon yakushimae) in Yakushima Island in Japan (Kiyono personal communication), a wild and unprovisioned capuchin monkey (Cebus libidinosus) nursing a marmoset (Izar et al., 2006), or a solitary lioness in the Samburu Game Reserve in Kenya 'adopting' and protecting oryx (Oryx beisa) calves (Douglas-Hamilton, 2002). This latter example is notable as it concerns a large-bodied carnivore and its typical prey species.

Studying cross-species interactions can allow us to better understand animal behavioural and cognitive flexibility and how individual species can positively or negatively affect other species around them. Characteristics such as body size, behavioural adaptations, cognitive ability and degree of curiosity likely affect a species' propensity to initiate interactions, in addition to sitespecific features such as wildlife abundance or habitat-type. More specifically, large-bodied species may be less inclined to flee from other animals (Cooper \& Stankowich, 2010) and may thus be more likely to initiate interactions with smaller species. Omnivorous species tend to show more varied interaction types than carnivores, as they are less likely to consider other species as prey and to be perceived as a threat. Lastly, cognitively advanced species might be expected to categorise different species (Matsuzawa et al., 2006) and show greater curiosity and flexibility with regard to sympatric wildlife (Mitani et al., 2010).

Chimpanzees (Pan troglodytes) provide an ideal model to explore patterns of cross-species interactions. While large-bodied, they are mainly ripe fruit specialists, yet capture and consume a 
variety of mammals, birds and other vertebrates (Wrangham, 1977; Nishida et al., 1979; Goodall,

1986). Chimpanzees are intelligent, highly dextrous and exhibit varied patterns of behaviour (for a detailed ethogram see Nishida et al., 2010). Population- or community-specific differences in behaviour have been documented across a variety of animal taxa, yet the scale of variation across social and tool-use domains singles out the chimpanzee (Whiten et al. 1999; McGrew, 2004; de Waal, 2005; Sanz et al., 2009). Anecdotal observations suggest the existence of numerous interaction types between chimpanzees and other species, and flexibility in chimpanzee responses to other species (Teleki, 1973). Nevertheless, most interactions between wild chimpanzees and sympatric vertebrate species are agonistic, and most research to date has focussed on chimpanzee predatory behaviour.

Chimpanzee communities and individuals vary in predation rates and hunting behaviour, often actively searching for prey and engaging in both cooperative and opportunistic hunts (for a review see Newton-Fisher, 2007). The availability of prey items, prey visibility, prey mobility, and seasonality influence communities' hunting patterns (Sugiyama, 1989; Uehara \& Ihobe, 1998; Gilby et al., 2006; Gilby \& Connor, 2010). Chimpanzee prey profiles are often extensive, ranging from birds to other primates (Wrangham \& van Zinnicq Bergmann-Riss, 1990; Uehara et al., 1992). Nevertheless, chimpanzees across Africa prey mostly upon colobine monkeys, especially red colobus, Procolobus spp. (Boesch \& Boesch, 1989; Stanford et al., 1994; Uehara, 1997; Mitani \& Watts, 2001). However, long-term data collated across various African study sites suggest community-specific differences in prey selectivity, whereby a species can be a preferred prey item at one site yet is ignored at another (Hosaka et al., 2001). This pattern challenges the assumption that prey species and availability is the unique factor that drives prey choice and emphasises the likely role of social learning in prey identification or the establishment of a "specialised prey image" (Boesch \& Boesch, 1989, pp.553; Hirata et al., 2011). Other aspects of prey behavioural ecology such as activity patterns and speed of movement may also affect interaction rates (Boesch \& Boesch, 1989). Moreover, chimpanzee prey selectivity can change over time (Hosaka et al., 
2001). At sites where preferred prey species are absent (i.e., Procolobus spp.), chimpanzees may target other less typical animals including galagos (Galago spp.), mongooses (Herpestidae family), and pangolins (Manis spp.) using innovative tools to access the prey (e.g., galago spearing in Fongoli, Senegal, Pruetz \& Bertolani, 2007).

Chimpanzees frequently occur in areas of anthropogenic influence throughout tropical Africa, and previous research demonstrates chimpanzees employ behavioural strategies to exploit forest-farm habitats (Hockings et al., 2012; Hockings \& McLennan, 2012). Heavily-impacted anthropogenic habitats generally offer fewer wildlife species. Although data are scarce, in such habitats chimpanzees may categorise animals differently to their counterparts in less disturbed environments with higher availability of preferred prey species. Chimpanzee populations living in human-impacted areas may react to domesticated species with indifference, aggression or with predatory intentions. For example, chimpanzees at Gombe in Tanzania aggressively pursued a domestic cat (Felis domesticus) that eventually escaped (Teleki, 1973), and chimpanzees in Uganda have been reported to depredate domesticated species, in particular chickens (McLennan, 2010). Chimpanzees often respond aggressively to domestic dogs (McLennan \& Hill, 2010). This particular species can represent a threat to chimpanzee safety in anthropogenic habitats (McLennan, 2010).

Chimpanzee interactions with other species are not restricted to predatory contexts, and although less frequent, they may interact with wildlife in diverse ways. Examples from captive populations (Ross et al., 2009) and anecdotal observations from the wild confirm that chimpanzees occasionally engage in social behaviours with other animals. Young individuals have been recorded to engage in playful behaviour with other vertebrate species (e.g., duiker, Cephalopus sp., Boesch \& Boesch, 1989; flying squirrel, Anomalurus derbianus, Boesch \& Boesch, 2000), even though these same species can sometimes become prey (e.g., baboons, Papio anubis, Goodall, 1986). Furthermore, chimpanzees may catch and kill animals without consuming the flesh, instead choosing to play with and groom the corpse (e.g., hyrax (Dendrohyrax dorsalis), Hirata et al., 
2001). Observations of wild and captive chimpanzees suggest that non-consumptive interactions are

mostly performed by juveniles or young adolescents (Teleki, 1973; Goodall, 1986; Boesch \& Boesch, 2000; Ross et al., 2009). Sabater Pi et al. (1993) witnessed bonobos (Pan paniscus) from the Lilungu region of the Democratic Republic of Congo (DRC) engaging in intimate, nonpredatory and long-lasting social activity with young colobus monkeys that they captured. Likewise at Wamba in DRC, Ihobe (1990) reported that adult male colobus monkeys groomed bonobos in an affiliative or playful fashion, while guenons (Cercopithecus ascanius; C. wolfi) frequently approached bonobos but did not initiate direct contact, and instead travelled, fed and rested in close proximity (Ihobe, 1997).

Long-term patterns of cross-species interactions have not been assessed comprehensively and quantitatively for any wild chimpanzee community. Furthermore, with the spread of humanimpacted environments, data that examine how animals modify their behavioural ecology to all aspects of anthropogenic landscapes are important for understanding species' behavioural flexibility (Hockings et al., 2012). Such data will also inform the degree to which different species can adapt to environmental changes. Here, we compile long-term data on chimpanzee interactions with sympatric species in a forest-farm matrix at Bossou, Guinea, West Africa, and examine interaction characteristics according to the species involved, chimpanzee-specific behaviours, and the actor's age-class. We test the following hypotheses:

1. If abundance of wildlife is low, including any chimpanzee typical prey species, then interaction rates between chimpanzees and other species will also be lower than for other populations inhabiting less disturbed areas, especially in a predatory context, with no effect of seasonality.

2. As with other chimpanzee populations, chimpanzees at Bossou will have distinct ways of interacting with wildlife species, which will determine whether or not chimpanzees engage in physical contact with other animals, the durations in which they do so, and the interaction type. 
3. As chimpanzees are attentive to conspecific behaviour, party size will positively correlate with

the number of individuals engaging in a cross-species interaction. Event duration will also increase with the number of interactants.

4. As with other chimpanzee populations, age differences should be evident in interaction type: adults will engage mostly in aggressive interactions while immatures will engage more playfully with other species.

\section{Material and methods}

Study site and subjects

The village of Bossou is situated in the forest region in south-eastern Republic of Guinea, West Africa (latitude $7^{\circ} 38^{\prime} 71.7^{\prime \prime} \mathrm{N}$; and longitude $8^{\circ} 29^{\prime} 38.9^{\prime \prime} \mathrm{W}$ ), approximately $6 \mathrm{~km}$ from the Nimba Mountain range (see Matsuzawa et al., 2011). The hills that constitute the chimpanzees' $15 \mathrm{~km}^{2}$ home range $\left(7 \mathrm{~km}^{2}\right.$ core area) are bisected by roads (Hockings et al., 2006) and covered in primary and secondary forest. Swidden (or 'slash-and-burn') agricultural practices have resulted in a mosaic of thicket, cultivated fields and orchards within and bordering the reserve (Figure 1). The climate at Bossou is classified as tropical wet seasonal; there is a clear wet season from March to October and a dry season from November to February (Takemoto, 2004; Hockings et al., 2009). From phenological data collected from 2004 to 2005 (see Hockings et al., 2009 for further details), months of high wild fruit availability were December through April, whereas low fruit availability months were May through November (Fruit Availability Index values: mean \pm SE, high vs. low; 4.8 \pm 0.6 vs. $1.4 \pm 0.1)$.

The village of Bossou is mainly inhabited by the Manon ethnic group. The Manon family that founded Bossou remains one of its most influential families and holds the sympatric chimpanzees as 
a sacred totem (Kortlandt, 1986; Yamakoshi, 2011). Due to these local cultural beliefs, humans and chimpanzees have coexisted over many generations. However, the forests sustain low abundance of medium- and large-bodied wildlife as a result of past human hunting activities (Sugiyama, 1989, 2004). Domesticated animal species, such as goats, sheep, chickens, dogs, roam and/or forage on the outskirts of the forest and within cultivated fields.

Chimpanzee community size at Bossou has varied over the years, but until 2003 remained stable at around 20 individuals (Sugiyama \& Fujita, 2011). During the thirteen-year period, 1997 to 2009, when direct data on cross-species interactions were collected (see below), community size ranged from 12 to 22 individuals. The chimpanzees are well habituated to observers.

$<$ Include Figure 1 here>

\section{Data Collection}

\section{Animal Interactions}

Direct observations of chimpanzee interactions with other live vertebrate species were recorded adlibitum by three researchers (KH, TH, SC) intermittently between 1997 and 2009. The combined total observation time was 9475 hours (low wild fruit availability months $=5709$ hours; high wild fruit availability months $=3766$ hours). Further data were compiled from published anecdotal observations of cross-species interactions at Bossou (hereafter 'published accounts'). Because researchers differed in the details provided in their reports for lack of a standard method for recording interaction data, we omitted some reported cases from our analyses. For example, when data on interaction duration were missing those cases were excluded (see data analysis section). 
All observed cross-species encounters that resulted in an interaction were recorded by

researchers. An interaction was recorded when behaviour was directed by an ape to a living animal of another vertebrate species. An interaction event started with the first directional behaviour and ended when the individual engaged in another activity not involving the target animal. An interaction session started with the first directional behaviour by the first individual and terminated when the last individual engaged in another activity not involving the same target animal. The duration of an interaction was the time in minutes between the start and end of an interaction. We omitted curiosity (i.e., intense and prolonged gaze in the direction of the animal) as an independent interaction type as it occurred in most interactions.

Interactions were categorised using a detailed ethogram of chimpanzee behaviour (sensu Nishida et al., 2010). First, each interaction session was coded as either involving direct physical contact or non-contact between an animal and a chimpanzee body part. Non-contact sessions were further categorised as play i.e., playful or toyful (play face), aggression (chase) or fear (fear grin). Contact interactions were further defined as capture, play (animal alive and/or with corpse), kill, or eat. Within each contact or non-contact category, interaction sessions sometimes involved more than one class, if many individuals interacted in different ways with an animal (for example, a contact interaction might involve capture, play and kill).

Numerous individuals sometimes interacted with the same animal throughout an interaction session. Each individual was coded to have only one interaction event per session, and the identity, age and sex of the actor were recorded. Non-contact events were categorised as playful, aggressive or fearful. Contact events were more diverse with numerous interaction types and distinct accompanying behaviours often co-occurring; all accompanying behaviours were noted. A predatory interaction was the capture and consumption of another vertebrate species. We noted the occurrence of meat-sharing, defined as an individual holding a food item but allowing another individual to eat part of that item. We also recorded if capture involved transport for a distance of greater than $100 \mathrm{~m}$. The habitat was categorised as 'natural' (i.e., in riverine, secondary or primary 
forest) or anthropogenic (i.e., in cultivated fields, in the village, on the roadside, or along human trails).

\section{Animal abundance}

Lacking long-term data on animal abundance at Bossou, including systematic recordings of animal traces/sightings, we employed a basic questionnaire to gauge wildlife abundance. Three researchers (KH, TH, SC) and three long-term research assistants (each with 10 to 15 years experience) independently rated the prevalence of all known mammalian species in the chimpanzees' core area. In August 2011, all six respondents completed a photograph-based questionnaire; methods were consistent with those employed in anthropological surveys (Newing et al. 2011). The questionnaire incorporated both Manon (local dialect) and French names for animals and a photograph of each animal to ensure accurate identification. All researchers and assistants conducted chimpanzee nestto-nest follows in all calendar months. Respondents were asked to include all sightings that occurred whilst following and/or trying to locate the chimpanzees, and to add ratings of any known species that was unintentionally excluded from the list. Given the close proximity with the village, observations of domesticated animal species were not included in the questionnaire. As no comprehensive survey of birds, reptiles, or fishes at Bossou exists, only the abundance of one species of owl and one species of viper with which the chimpanzees were recorded to interact were rated within those classes.

Respondents rated wildlife abundance on a four-point scale based on frequency of observations per month: (1) 'rare' applied to a species never observed or seen less than once per six research months, (2) 'occasional' applied to one observation every one to six months, (3) 'frequent' applied to at least one observation per month, and (4) 'very frequent' applied to more than 10 observations per month (method adapted from Ross et al., 2009). 
Data Analysis

Data were analysed using SPSS version 19. If data were not normally distributed, we either employed non-parametric statistics or transformed the data to achieve normality and meet the assumptions of parametric analyses (Sokal \& Rohlf, 1995). Due to low numbers of observations and counts in certain categories, a statistical test could not always be done. All the hypotheses considered were two-tailed and tested at $\alpha=0.05$.

We tested inter-rater reliability in animal abundance ratings between researchers. Researchers showed complete agreement for 11 of 18 species, and never differed by more than one adjacent rating (e.g., between rare and occasional, or frequent and very frequent). The median category per species was calculated from all six questionnaire responses, and was selected to represent a species' relative abundance. A Pearson's Chi-squared test was used to assess whether there was a difference in the number of interactions per animal abundance category, as the expected frequencies were too small to further assess variations in abundance by animal class. We failed to identify the species with which chimpanzees interacted in four cases (one mouse, two fledgling birds, one snake), so data on these encounters were excluded from the abundance analyses. Interaction rates were calculated by dividing the number of interaction sessions by total direct observation hours and multiplying by 100 (i.e., rate per 100 hours). We also controlled for high and low wild fruit availability seasons. To test whether cross-species interaction rates differed between seasons, a binomial test was employed using a test proportion of 0.6 to account for $60 \%$ bias in observation time occurring during periods of fruit scarcity.

A Kruskal-Wallis test was used to assess whether interaction durations differed according to animal class (mammal, bird, reptile - no interactions were recorded with amphibians or fishes). To test whether contact or non-contact behaviour affected the interaction duration (data available from 
29 of 32 interactions), we performed an ANOVA using log-transformed data (with an added constant of 1 to the variable). We used Kendall rank correlations to assess the relationship between the number of individuals that interacted within an event and (i) party size (excluding infants; see Hockings et al., 2012, for details on definitions of party size), and (ii) the duration of an event. A Freeman-Halton extension of the Fisher's exact test for $2 \times 3$ contingency tables was used to test whether there were differences in contact and non-contact interactions between the three animal classes. Binomial tests were employed to assess whether an animal was (i) killed and (ii) eaten more than expected by chance (test proportion 0.5).

Within an interaction session, interaction events per individual were analysed to allow examination of age- and sex-differences in behaviours. Following Sugiyama (2004), individuals of 4-7 years of age were classed as juveniles, 8-11 years as adolescents, and individuals older than 11 years as adults. Infants (0-3 years) were excluded from analyses. 'Immatures' refers to juveniles and adolescents. Interaction duration per individual was non-normally distributed and could not be transformed to achieve normality, so we relied on non-parametric analyses of the data. To assess if immatures and adults differed in their interaction duration per event, Mann-Whitney tests were performed. For contact and non-contact interaction events combined, a Fisher's Exact test was used to test whether immatures and adults varied in frequency of playful interactions. For contact interactions only, Pearson's Chi-squared tests were performed to assess whether immatures and adults differed in their likelihood of capturing and killing an animal. Fisher's Exact tests were used to see if these age-classes varied in their probability of eating and playing with the corpse. For analyses of food-sharing frequencies, only the 11 observations in which an animal was consumed and party size was greater than one individual, were included.

\section{Results}


Data on 32 interaction sessions were obtained, of which 10 were extracted from previouslypublished material (Table 1). Twenty-one interaction sessions (65\%) were with mammals, five with birds $(16 \%)$ and six with reptiles (19\%); interactions with amphibians or fishes were never recorded. Twenty-seven (84\%) interactions concerned wild animals. Of those, 96.3\% (26 of 27) occurred in 'wild' parts of the habitat. Chimpanzees interacted with two domesticated species, and four of five of these sessions took place in 'anthropogenic' parts of the habitat.

Most wildlife species at Bossou are nocturnal and are only rarely or occasionally observed (see Table 2); squirrels were the only wild species rated as 'very often' observed. Aside from chimpanzees, the only non-human primates recorded at Bossou included a species of potto and galago; monkeys are absent from the core area of the Bossou chimpanzee community. Chimpanzees interacted with seven of the 17 mammalian wildlife species confirmed present at Bossou; these included species from five mammalian orders, i.e., Artiodactyla, Hyracoidea, Pholidota, Primata, and Rodentia. No interactions were recorded between chimpanzees and wildlife from the Carnivora and Insectivora. Most interactions with wild mammals concerned rarely-observed species (10 of 15 sessions; see Figure 2). Chimpanzees were confirmed interacting with only one species of bird (rated as occasionally observed) and one species of reptile (rated as frequently observed); although within both classes, interactions with unidentified species were also recorded. There was no significant difference in the number of interactions per animal abundance category (Pearson's Chisquare test: $\left.\chi^{2}(3)=4.65, \mathrm{p}=0.20\right)$.

$<$ Include Figure 2 here>

Chimpanzees interacted with other species at a rate of 0.23 interactions/100 hours (22 interaction sessions from 9474 observation hours), about one interaction per 400 observation hours. Seventeen of 22 direct observations occurred during low wild fruit availability months, and interaction rates 
were higher during periods of wild fruit scarcity (interaction rate per $100 \mathrm{hrs}$ : $0.30 \mathrm{vs}$. 0.13 ); this difference between seasons approached significance (binomial (0.60), $\mathrm{p}=0.072$ ). Predatory interactions occurred at a rate of 0.05 interactions/100 hours (5 sessions from 9474 observation hours).

\section{Variations between cross-species interactions}

Mean interaction duration was 90 minutes $(\mathrm{SE}=35.06)$. Although interaction durations appeared to vary by animal class (Figure 3), these differences were not significant (Kruskal-Wallis test, H $=2.98, \mathrm{df}=2, \mathrm{p}=0.23$ ). However, there was a significant effect of physical contact on interaction session duration (ANOVA, F $(1,27)=40.38, \mathrm{p}<0.001)$; contact interactions were substantially longer than non-contact interactions (mean duration \pm SE: $183.29 \pm 64.84$ vs. $4.06 \pm 1.37$; Figure 4). Although session duration was not significantly influenced by the number of individuals that interacted with the animal (Kendal tau $=0.27, \mathrm{p}=0.067$ ), there was a positive correlation between the number of individuals that interacted with an animal and party size (Kendall rank correlation tau $=0.44, \mathrm{p}<0.01)$.

<Include Figures 3 and 4 here >

Contact interactions were always initiated by a chimpanzee and only ever involved one target animal. Chimpanzees tended to make physical contact with only particular species (interactions with hyraxes were the exception, see Table 3). Exactly half of all sessions (16 of 32) involved contact, and contact occurred with six vertebrate animal orders. Physical contact with mammals depended on the animal class concerned. Contact was always made during interactions with birds, but chimpanzees were never seen to make direct contact with snakes (Fisher's exact test: $\mathrm{p}<0.01$; 
Table 3). During non-contact interactions with snakes all individuals showed fear responses.

Between 1997 and 2009 no physical contact was ever seen between chimpanzees and any domesticated species (but see Supplementary Video for additional observation).

The nature of physical contact with mammals was dependent on the species involved (Table 1; see Supplementary Video). However, during contacts, the animal was always killed (16 of 16 interaction sessions, binomial: $\mathrm{p}<0.01$ ). The captured animal was eaten in 10 of 16 interaction sessions (binomial, $\mathrm{p}=0.45$ ), and during five of 16 sessions the chimpanzee played with the animal. Three involved initial play with the living animal and subsequently with its corpse (two of three sessions involved a bird), and two were killed before play began. In three of 16 sessions, the corpse of the dead animal was carried to a different place; once a potto corpse was transported by an immature for 1.8km (Tables 1 and 4, session 27). When an animal was eaten, we saw food-sharing in four of 10 sessions; only two species were shared, pangolin (three of seven events involved sharing between all age- and sex-classes) and potto ( 1 of 1 event involved sharing from one adult male to another). Bird meat was never shared.

\section{Age-specific interaction variations}

On an event basis, there was no overall difference in interaction duration for immatures and adults (Mann-Whitney, $\mathrm{Z}=-0.29, \mathrm{p}=0.77$ ). Over all interaction events (contact and non-contact combined), immatures were significantly more likely to engage in play with other species than adults (Fisher's exact test, $\mathrm{p}<0.01$ ): $35 \%$ of all cross-species interaction events involving immatures were playful (14 of 40 events), whereas adults never engaged in playful interactions with other species ( 0 of 48 events). For contact interactions, we found no significant difference in the capture and kill frequencies of immatures and adults (Capture, $\chi^{2}(1)=0.76, p=0.39 ;$ Kill, $\chi^{2}(1)=0.85, p=0.36$ ). However, these age classes varied in their meat consumption frequencies (Fisher's exact test, 
$\mathrm{p}<0.01$ ) and play with captured animals (Fisher's exact test, $\mathrm{p}<0.01$ ): adults were significantly more

likely to consume a captured animal than were immatures, and immatures were more likely to play with a captured animal than were adults. Immatures engaged in three non-contact play events with squirrels, and three non-contact play events (over two sessions) with a dog and goats. Contact play events among immatures were observed with four species, and in three of five sessions the animal was not eaten (see Table 1).

Distinct accompanying behaviours occurred during 11 of 34 contact interactions, 10 of which involved immatures. Overall 14 accompanying behavioural patterns were exhibited (see Table 4), often in combination within an interaction (mean \pm SD number per event $=2.64 \pm 1.63$, range: $1-6)$.

\section{Discussion}

Most wild chimpanzee populations live in tropical Africa where sympatry with other wildlife species is high (Russak \& McGrew, 2008). However, our data confirm that the abundance of wildlife occupying the anthropogenically-impacted habitat at Bossou is low. Past human hunting activities are the most probable explanation for their scarcity. The forests of Bossou are also isolated (being $6 \mathrm{~km}$ from the Nimba mountain range), which likely restricts species' movement and impacts reproduction. As predicted, the depleted abundance of wildlife, in particular chimpanzee typical prey species, such as colobus monkeys, is reflected in both the low interaction rates and the low number of species with which chimpanzees interact. Interactions were confirmed with only nine species (mostly mammals, but also birds and reptiles), and chimpanzees mainly interacted with rarely-sighted mammals. An interaction was recorded about every 400 observation hours, and a predation was recorded once every 2,000 hours. This is significantly less than reported at other research sites. For example, at Gombe in Tanzania chimpanzees preyed on more than 25 vertebrate 
species with 4.65 kills per 100 hours between 1972-1975 (Wrangham \& van Zinnicq Bergmann-

Riss, 1990). At Mahale in Tanzania, 100 predation episodes were observed over 729 study days in 1983-1990, and the chimpanzees consumed 16 mammalian species (Uehara et al., 1992). In agreement with preliminary observations by Sugiyama (1989), our longer-term data-set confirms that chimpanzees at Bossou show very low rates of hunting compared to other communities, probably as a consequence of inhabiting an anthropogenic habitat with a low occurrence of suitable prey species.

Cross-species interaction rates in more recent years did not vary by season, although there was a slight bias towards observing more interactions during rainy season months when wild fruits were scarce. To evaluate how animals are affected by seasonal differences including wild food availability would require further data on abundance, distribution and behaviour of wild animals at Bossou, especially nocturnal species. At present, it is hard to evaluate whether or not interaction rates have changed over the years, due to variation in chimpanzee habituation levels. Further data will also allow evaluation of the relative impact of chimpanzee predation and anthropogenic factors on the behaviour and persistence of sympatric wildlife. Most interactions occurred in the more natural parts of the habitat, where wildlife is likely to occur at higher densities, away from human activities. However more recently, interactions with domesticated species were recorded in 'anthropogenic' parts of the habitat. Chimpanzees frequently encounter domesticated species as they utilise fields and village areas to feed on crops (Hockings et al., 2009) and cross roads to access different parts of their range (Hockings et al., 2006). Domesticated species are mostly found in predictable locations and are likely easier to capture than wild species. Although data are lacking on long-term changes in wild and anthropogenic habitat use by chimpanzees, we predict that as the number and diversity of domesticated animals rises with a growing human population, these interactions will increase in frequency. As with crop-raiding behaviours by animals, attacks on domesticated species will compromise biodiversity conservation initiatives by generating negative perceptions of wildlife and may threaten rural people's economic security. 
We noted numerous differences in the nature of chimpanzee interactions with different

animals. Our observations, although limited, suggest that chimpanzees generally choose either to make direct contact with a species or not. Cross-species interactions that involved direct physical contact lasted longer than non-contacts, which emphasise differences in the complexities of these interactions. Although interaction duration was not affected by party size, when party size was larger more individuals interacted with an animal; this is consistent with the curiosity that chimpanzees exhibit towards the behaviour of conspecifics and provides an environment for the social transmission of interaction behaviours.

Interactions with mammals showed the greatest diversity. The only interactions that resembled 'typical' predatory episodes (intense excitement and begging) albeit opportunistic, involved pangolins and a potto, another primate species. It is probable that for certain species, especially those that are fast-moving such as squirrels, contact interaction rates were low due to difficulties in capturing the prey. Interactions with birds always involved physical contact, presumably because the main species targeted was easy to catch and harmless to chimpanzees. Snakes, more specifically vipers, were often encountered, but interactions never involved contact, and chimpanzees always reacted fearfully: vipers are notoriously slow-moving and large-bodied snakes. On one occasion (session no. 30), an adult male saw a quick-moving snake, and after his initial fear reaction and after the snake had gone, he actively searched for the snake whilst exhibiting intense signs of stress including rough self-scratching (Hockings et al., 2007). Unlike the rest of the party who had not noticed the snake, he continued for the rest of the day to react as if he repeatedly detected it (see Supplementary Video). Chimpanzees varied in their behavioural reactions to different species which supports the idea that chimpanzees categorise sympatric animals.

Whenever an animal was captured, it was eventually killed, sometimes deliberately and in other instances apparently unintentionally through rough play behaviour. However, the animal was not always eaten. When an animal was consumed, instances of begging or active sharing with other 
party members concerned only two mammalian species, pangolin and potto. In the case of the potto,

the second-ranked adult male shared meat with the alpha male; this contrasts with other adult foodsharing events observed at Bossou, which are predominantly from adult males to females (e.g., crops, Hockings et al., 2007). For all other species, meat transfers occurred via retrieval of dropped or discarded pieces, i.e., scrounging. The few hunts seen at Bossou were opportunistic and solitary and occurred when an animal was accidentally encountered, and not in response to other ecological and social factors as reported from other sites (e.g., at Gombe, Gilby \& Wrangham, 2007).

Between 1997 and 2009, contact was never recorded between chimpanzees and domesticated species; however, more recently an adult male chimpanzee was observed capturing a chicken (see supplementary Video). The observers intervened and the chimpanzee dropped the chicken. This action was taken to minimise potential conflict with local villagers (Hockings \& Humle, 2009). As with other wild chimpanzee communities, we predict that as prey categories are not fixed, chimpanzees at Bossou may increasingly view domesticated species as prey. There are unconfirmed reports of chimpanzees at other sites in Guinea eating goats and chickens (Kormos et al., 2003; McLennan, 2010), which potentially exacerbates conflict with local people. As with large-bodied carnivore attacks on domesticated species in anthropogenic habitats (Inskip \& Zimmerman, 2009), domesticated animals will likely constitute highly accessible prey to chimpanzees, and the potential for elevating conflict levels with humans is high. Although interactions between domesticated dogs and wild primates vary (Anderson, 1986; McLennan \& Hill, 2010), it is likely that increasing spatial overlap will cause aggressive interactions to intensify and increase the likelihood of injury to chimpanzees and dogs.

Adults and immatures did not differ in the duration of their interactions with other species and both age-classes captured and killed animals equally often; nevertheless other aspects of their interactions were different. Adults more often consumed a captured animal, and immatures more often engaged in contact and non-contact playful behaviours with other species, whereas adults never did. This is consistent with how different age classes interact with members of their own 
species, with immatures more frequently engaging in play (Hayaki, 1985). Immatures also exhibited

various distinctive accompanying behaviours during cross-species interactions, whereas adults rarely did so. These behaviours were flexible and diverse, including building a nest to interact solitarily with the animal, heel-tapping on or in proximity to the animal, rubbing the corpse on the genitals, grooming the corpse, and systematically dropping and retrieving the animal. Some of these behavioural patterns seem to be adapted from other situations (e.g., heel-tapping to get an individual's attention) and others are specific to cross-species interactions (e.g., genital-rubbing using the corpse).

Play behaviour mostly occurs among immature members of phylogenetically closely-related species (e.g., within the primates, Goodall, 1986), especially those in frequent mixed-associations, but such interactions are two-way and rarely result in death. However, interactions between more distantly related species are seldom reported. It is not possible to compare rates of cross-species play interactions between chimpanzee populations as anecdotal observations have not been compiled. It is thus unknown if immature chimpanzees at Bossou engage in interactions more frequently or if their behaviours are more diverse than in other populations. The lack of alternative prey species may encourage younger individuals at Bossou to engage in more exploratory behaviours with other species. Unlike individuals from other communities that regularly observe hunting, chimpanzees at Bossou have few opportunities to learn about sympatric animals through observations of other group members. However further comparative data from other long-term chimpanzee research sites are needed to test this hypothesis.

In summary, our results show that chimpanzees show diverse interactions with other species, and this diversity strongly suggests that chimpanzees demonstrate species-specific behavioural patterns that depend on the age-class of the interactant. Like many other chimpanzee behaviours, for example, the differential exploitation of invertebrates such as ants and termites (Humle \& Matsuzawa, 2002), animal categories are probably socially learnt through careful observations of 
other group members and sometimes through prolonged exploratory behaviours. As such they will be disseminated across generations and form over time cultural variants.

The rapidly changing environments that numerous wildlife populations inhabit will present new domesticated prey species. However, emerging issues associated with inhabiting anthropogenic environments, including retaliatory killings of animals in response to conflict with humans and increased likelihood of disease transmission will certainly outweigh any benefits to wildlife (Hockings \& Humle, 2009). Future management strategies aimed to conserve wildlife populations precariously residing in humanised habitats must anticipate behavioural flexibility in response to changing landscapes.

\section{Acknowledgements}

Thanks to the DNRST and SA Gaspard, Director of the IREB, Guinea. We would also like to thank the local assistants for their invaluable help and Bossou villagers for continuing support. We are grateful to WC McGrew and M McLennan for their helpful comments. This work was supported by a post-doctoral research grant to KH from Fundação para a Ciência e a Tecnologia, Portugal, and MEXT grant \#20002001, JSPS-HOPE and JSPS-gCOE (A06, Biodiversity) to TM.

\section{References}

Anderson, J.R. (1986). Encounters between domestic dogs and free-ranging non-human primates. Appl. Anim. Behav. Sci. 15: 71-86. 
Boesch, C. \& Boesch, H. (1989). Hunting behavior of wild chimpanzees in the Taï National Park. -

Am. J. Phys. Anthropol. 78: 547-573.

Boesch, C. \& Boesch-Achermann, H., eds (2000). The Chimpanzees of the Taï Forest: Behavioural Ecology and Evolution. - Oxford University Press, Oxford.

Carvalho, S., Yamanasi, Y., Yamakoshi, G. \& Matsuzawa, T. (2010). Bird in the hand: Bossou chimpanzees (Pan troglodytes) capture West African wood-owls (Ciccaba woodfordi) but not to eat. - Pan Africa News. 17: 6-9.

Cooper, W.E. \& Stankowich, T. (2010). Prey or predator? Body size of an approaching animal affects decisions to attack or escape. - Behav. Ecol. 21: 1278-1284.

de Waal, F.B.M. (2005). A century of getting to know the chimpanzee. - Nature 437: 56-59.

Douglas-Hamilton, S. (2002). The amazing story of the lioness and 'her' baby Oryx. http://www.olerai.com/detail/lioness-and-oryx.htm. Accessed 6 January 2012.

Endler, J.A. (1991). Interactions between predators and prey. - In: Behavioral ecology, 3rd edn. (Krebs, J.R. \& Davies, N.B., eds.). Blackwell Scientific Pubs, Oxford, p. 169-196.

Gilby, I.C. \& Connor, R.C. (2010). The role of intelligence in group hunting: Are chimpanzees different from other social predators? - In: The Mind of the Chimpanzee: Ecological and Experimental Perspectives (Lonsdorf, E.V., Ross, S.R. \& Matsuzawa, T., eds.). University of Chicago Press, Chicago, IL, p. 220-233.

Gilby, I.C. \& Wrangham, R.W. (2007). Risk-prone hunting by chimpanzees (Pan troglodytes schweinfurthii) increases during periods of high diet quality. - Behav. Ecol. Sociobiol. 61: 17711779 .

Gilby, .IC., Eberly, L.E., Pintea, L. \& Pusey, A.E. (2006). Ecological and social influences on the hunting behaviour of wild chimpanzees, Pan troglodytes schweinfurthii. - Anim. Behav. 72: 169-180.

Goodall, J. (1986). The Chimpanzees of Gombe: Patterns of Behavior. - Harvard University Press, Cambridge, MA. 
Hayaki, H. (1985). Social play of juvenile and adolescent chimpanzees in the Mahale Mountains

National Park, Tanzania. - Primates 26: 343-360.

Hirata, S., Yamakoshi, G., Fujita, S., Ohashi, G. \& Matsuzawa, T. (2001). Capturing and toying with hyraxes (Dendrohyrax dorsalis) by wild chimpanzees (Pan troglodytes) at Bossou, Guinea. - Am. J. Primatol. 53: 93-97.

Hirata, S. \& Mizumo, Y. (2011). Animal Toying. - In: The chimpanzees of Bossou and Nimba (Matsuzawa, T., Humle, T. \& Sugiyama, Y., eds.). Springer, Tokyo, p. 137-141.

Hockings, K.J. \& Humle, T. (2009). Best practice guidelines for the prevention and mitigation of conflict between humans and great apes. - IUCN/SSC Primate Specialist Group, Gland, Switzerland.

Hockings, K.J., Humle, T., Anderson, J.R., Biro, D., Sousa, C., Ohashi, G. \& Matsuzawa, T. (2007). Chimpanzees share forbidden fruit. - PloS ONE 2: e886.

Hockings, K.J., Anderson, J.R. \& Matsuzawa, T. (2009). Use of wild and cultivated foods by chimpanzees at Bossou, Republic of Guinea: feeding dynamics in a human-influenced environment. - Am. J. Primatol. 71: 636-646.

Hockings, K.J., Anderson, J.R. \& Matsuzawa, T. (2012). Socioecological adaptations by chimpanzees, Pan troglodytes verus, inhabiting an anthropogenically impacted habitat. - Anim. Behav. 83: 801-810.

Hockings, K.J. \& McLennan, M. (2012). From forest to farm: systematic review of cultivar feeding by chimpanzees - management implications for wildlife in anthropogenic landscapes. - PloS ONE. In press.

Hosaka, K., Nishida, T., Hamai, M., Matsumoto-Oda, A. \& Uehara, S. (2001). Predation of mammals by chimpanzees of the Mahale Mountains, Tanzania. - In: All apes great and small (Galdikas, B., Briggs, N., Sheeran, L., Shapiro, G. \& Goodall, J., eds.). Kluwer Academic Publishers, New York, p. 107-130. 
Humle, T. \& Matsuzawa, T. (2002). Ant-dipping among the chimpanzees of Bossou, Guinea, and some comparisons with other sites. - Am. J. Primatol. 58: 133-148.

Ihobe, H. (1997). Non-antagonistic relations between wild bonobos and two species of guenons. Primates 38: 351-357.

Ihobe, H. (1990). Interspecific interactions between wild pygmy chimpanzees (Pan paniscus) and red colobus (Colobus badius). - Primates 31: 109-112.

Inskip, C. \& Zimmerman, A. (2009). Human-felid conflict: a review of patterns and priorities worldwide. - Oryx 43:18-34.

Izar, P., Verderane, M.P., Visalberghi, E., Ottoni, E., de Oliveira, M.G., Shirley, J. \& Fragaszy, D. (2006). Cross-genus adoption of a marmoset (Callithrix jacchus) by wild capuchin monkeys (Cebus libidinosus): case report. - Am. J. Primatol. 68: 692-700.

Kormos, R., Boesch, C., Bakarr, M.I. \& Butynski, T.M. (2003). West African Chimpanzees: Status Survey and Conservation Action Plan. - IUCN/SSC Primate Specialist Group, Gland, Switzerland.

Kortlandt, A. (1986). The use of stone tools by wild-living chimpanzees and earliest hominids. - J. Hum. Evol. 15: 77-132.

Matsuzawa, T., Tomonaga, M. \& Tanaka, M., eds (2006). Cognitive development in chimpanzees. - Springer-Verlag, Tokyo.

Matsuzawa, T., Humle, T. \& Sugiyama, Y., eds (2011). The chimpanzees of Bossou and Nimba. Springer, Tokyo.

McGrew, W.C., ed (2004). The cultured chimpanzee: reflections on cultural primatology. Cambridge University Press.

McLennan, M.R. (2010). Chimpanzee ecology and interactions with people in an unprotected human-dominated landscape at Bulindi, western Uganda. - Oxford Brookes University, UK, $\mathrm{PhD}$ thesis. 
McLennan, M.R. \& Hill, C.M. (2010). Chimpanzee responses to researchers in a disturbed forestfarm mosaic at Bulindi, western Uganda. - Am. J. Primatol. 72: 907-918.

Mitani, J.C. \& Watts, D. (2001). Why do chimpanzees hunt and share meat? - Anim. Behav. 61: 915-924.

Mitani, J.C., Amsler, S. \& Sobolewski, M. (2010). Chimpanzee minds in nature. - In: The Chimpanzee Mind (Lonsdorf, E., Ross, S. \& Matsuzawa, .T., eds.). University of Chicago Press, Chicago, p. 181-191.

Newing, H., ed (2011). Conducting Research in Conservation: A Social Science Perspective. Routledge.

Newton-Fisher, N.E. (2007). Chimpanzee hunting behaviour. - In: Handbook of Physical Anthropology (Henke, W., Rothe, H. \& Tattersall, I., eds.). Springer, p. 1295-1320.

Nishida, T., Uehara, S. \& Nyundo, R. (1979). Predatory behavior among wild chimpanzees of the Mahale Mountains. - Primates 20: 1-20.

Nishida, T., Zamma, K., Matsusaka, T., Inaba, A. \& McGrew, W.C., eds (2010). Chimpanzee behavior in the wild: An audio-visual encyclopedia. - Springer-Verlag, Tokyo.

Pruetz, J.D. \& Bertolani, P. (2007). Savanna chimpanzees (Pan troglodytes verus) hunt with tools. Curr. Biol. 17: 412-417.

Ross, S.R., Holmes, A.N. \& Lonsdorf, E.V. (2009). Interactions between zoo-housed great apes and local wildlife. - Am. J. Primatol. 71: 458-465.

Russak, S.M. \& McGrew, W.C. (2008). Chimpanzees as fauna: comparisons of sympatric large mammals across long-term study sites. - Am. J. Primatol. 70: 402-409

Sabater Pi, G., Bermejo, M., Illera, G. \& Vea, J.J. (1993). Behavior of bonobos (Pan paniscus) following their capture of monkeys in Zaire. - Int. J. Primatol. 14: 797-804.

Sanz, C., Call, J. \& Morgan, D. (2009). Design complexity in termite-fishing tools of chimpanzees (Pan troglodytes). - Biol. Lett. 5: 293-296. 
Sokal, R.R. \& Rohlf, F.J., eds (1995). The Principles and Practice of Statistics in Biological Research, $3^{\text {rd }}$ edn. - Freeman and Company, New York.

Stanford, C.B., Wallis, J., Matama, H. \& Goodall, J. (1994). Patterns of predation by chimpanzees on red colobus monkeys in Gombe National Park, 1982-1991. - Am. J. Phys. Anthropol. 94: $213-228$.

Sugiyama, Y. \& Fujita, S. (2011). The demography and reproductive parameters of Bossou chimpanzees. - In: The chimpanzees of Bossou and Nimba (Matsuzawa, T., Humle, T. \& Sugiyama, Y., eds.). Springer, Tokyo, p. 23-34.

Sugiyama, Y. (1981). Observations on the population dynamics and behavior of wild chimpanzees at Bossou, Guinea, in 1979-1980. - Primates 22: 435-444.

Sugiyama, Y. (1989). Description of some characteristic behaviors and discussion on their propagation process among chimpanzees of Bossou, Guinea. - In: Behavioral studies of wild Chimpanzees at Bossou, Guinea (Sugiyama, Y., ed.). Inuyama, Kyoto University Research Institute, p. 43-47.

Sugiyama, Y. (2004). Demographic parameters and life history of chimpanzees at Bossou, Guinea. - Am. J. Phys. Anthropol. 124: 154-165.

Takemoto, H. (2004). Seasonal change in terrestriality of chimpanzees in relation to microclimate in the tropical forest. - Am. J. Phys. Anthropol. 124: 81-92.

Teleki, G. (1973). Notes on chimpanzee interactions with small carnivores in Gombe National Park, Tanzania. - Primates 14: 407-412.

Uehara, S. \& Ihobe, H. (1998). Distribution and abundance of diurnal mammals, especially monkeys, at Kasoje, Mahale Mountains, Tanzania. - Anthropol. Sci. 106: 349-369.

Uehara, S. (1997) Predation on mammals by the chimpanzee (Pan troglodytes). - Primates 38: 193214.

Uehara, S., Nishida, T., Hamai, M., Hasegawa, T., Hayaki, H., Huffman, M.A., Kawanaka, K., Kobayashi, S., Mitani, J.C., Takahata, Y., Takasaki, H. \& Tsukahara, T. (1992). Characteristics 
of predation by the chimpanzees in the Mahale Mountains National Park, Tanzania. - In: Topics

in Primatology, Vol. 1, Human Origins (Nishida, T., McGrew, W.C., Marler, P., Pickford, M. \& de Waal, F.B.M., eds.). University of Tokyo Press, Tokyo, p. 143-158.

Whiten, A., Goodall, J., McGrew, W.C., Nishida, T., Reynolds, V., Sugiyama, Y., Tutin, C.E., Wrangham, R. \& Boesch, C. (1999). Cultures in chimpanzees. - Nature 399: 682-685.

Wrangham, R.W. \& van Z. Bergmann Riss, E. (1990). Rates of predation on mammals by Gombe chimpanzees. - Primates 31: 157-170.

Wrangham, R.W. (1977). Feeding behaviour of chimpanzees in Gombe National Park, Tanzania. In: Primate Ecology: Studies of Feeding and Ranging Behaviour in Lemurs, Monkeys and Apes (Clutton-Brock, T.H., ed.). London Academic Press, London, p. 504-538.

Yamakoshi, G. (2011). The "prehistory" before 1976: looking back on three decades of research on Bossou chimpanzees. - In: The chimpanzees of Bossou and Nimba (Matsuzawa, T., Humle, T. \& Sugiyama, Y., eds.). Springer, Tokyo, p. 35-44. 


\section{Figure legends}

Figure 1. A map of the study site (Bossou), showing the village, roads (dashes) and the three main forested hills that constitute the chimpanzees' core range area. Cultivated areas within and surrounding the chimpanzees' core area in 2005 are highlighted in dark grey.

Figure 2. Frequency of interactions by animal class (mammal, $n=15$; bird, $n=3$; reptile, $n=5$ ) and their rated observation frequency (or abundance).

Figure 3. Interaction duration with mammals, birds and reptiles. Extreme $\left({ }^{*}\right)$ and outlier $\left({ }^{\circ}\right)$ events are highlighted.

Figure 4. Duration of contact $(n=14)$ and non-contact $(n=15)$ interactions. Data are log transformed.

\section{Supplementary information}

Supplementary Video. Four short clips of cross-species interactions: (1) an immature chimpanzee plays with the plucked corpse of an African wood owl (interaction session 31), (2) the alpha male exhibits searching and fearful behaviours after having observed a fastmoving snake (interaction session 30), (3) an adult male feeds on potto meat, firstly consuming the hands followed with the intestines of the animal (interaction session 27), (4) an adult male chases and captures a domestic chicken in a farm (additional data by KH). 


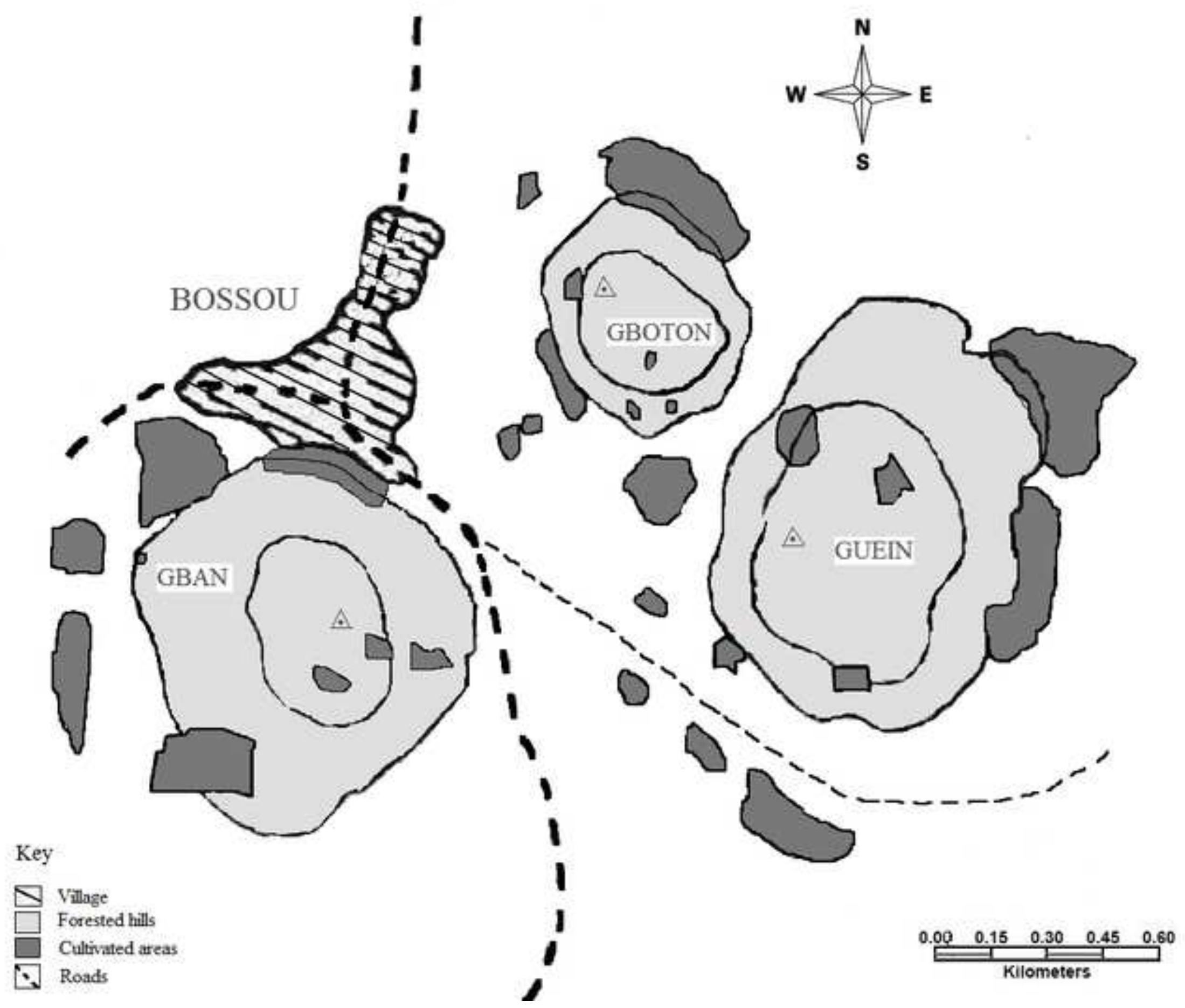




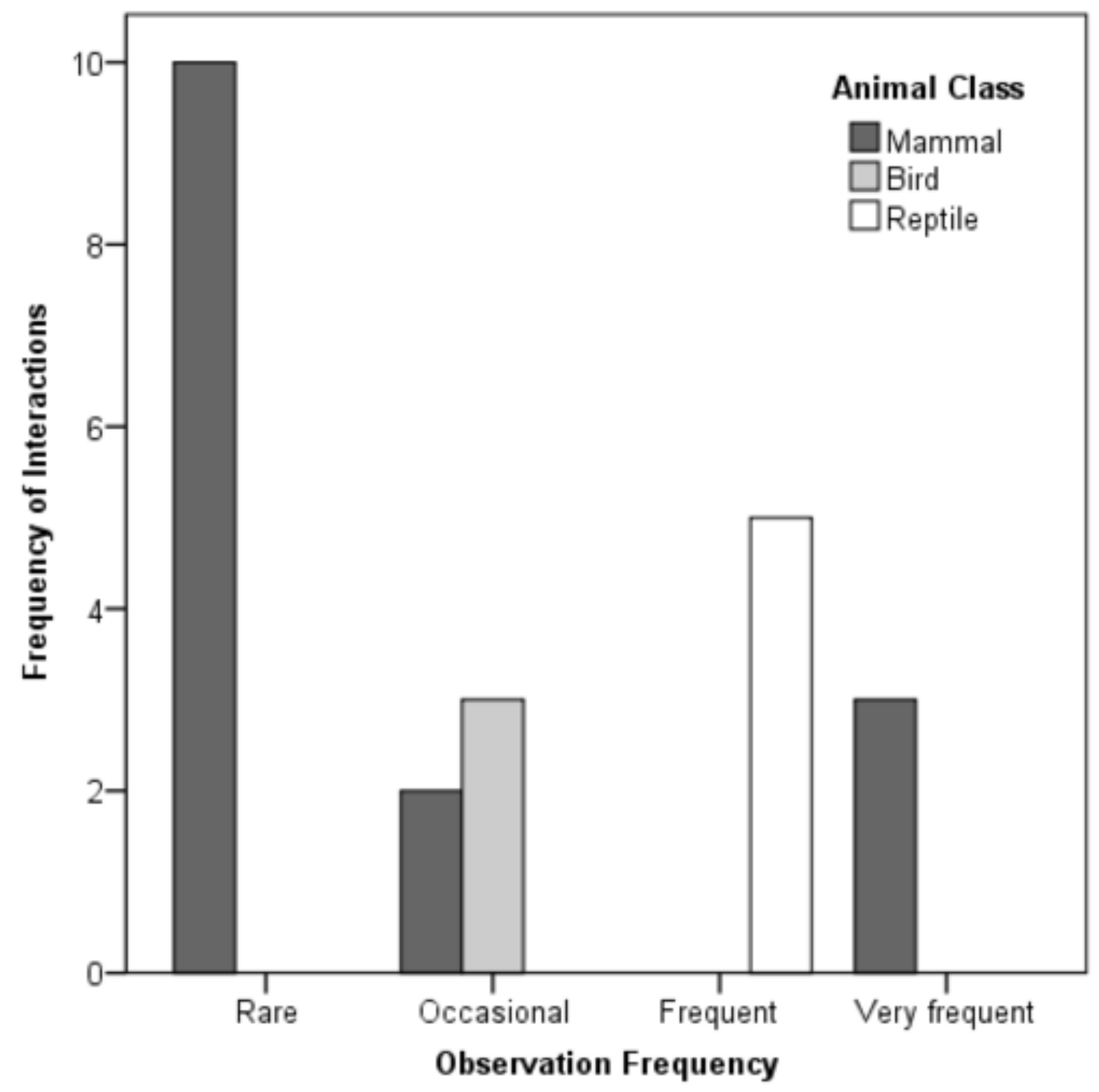




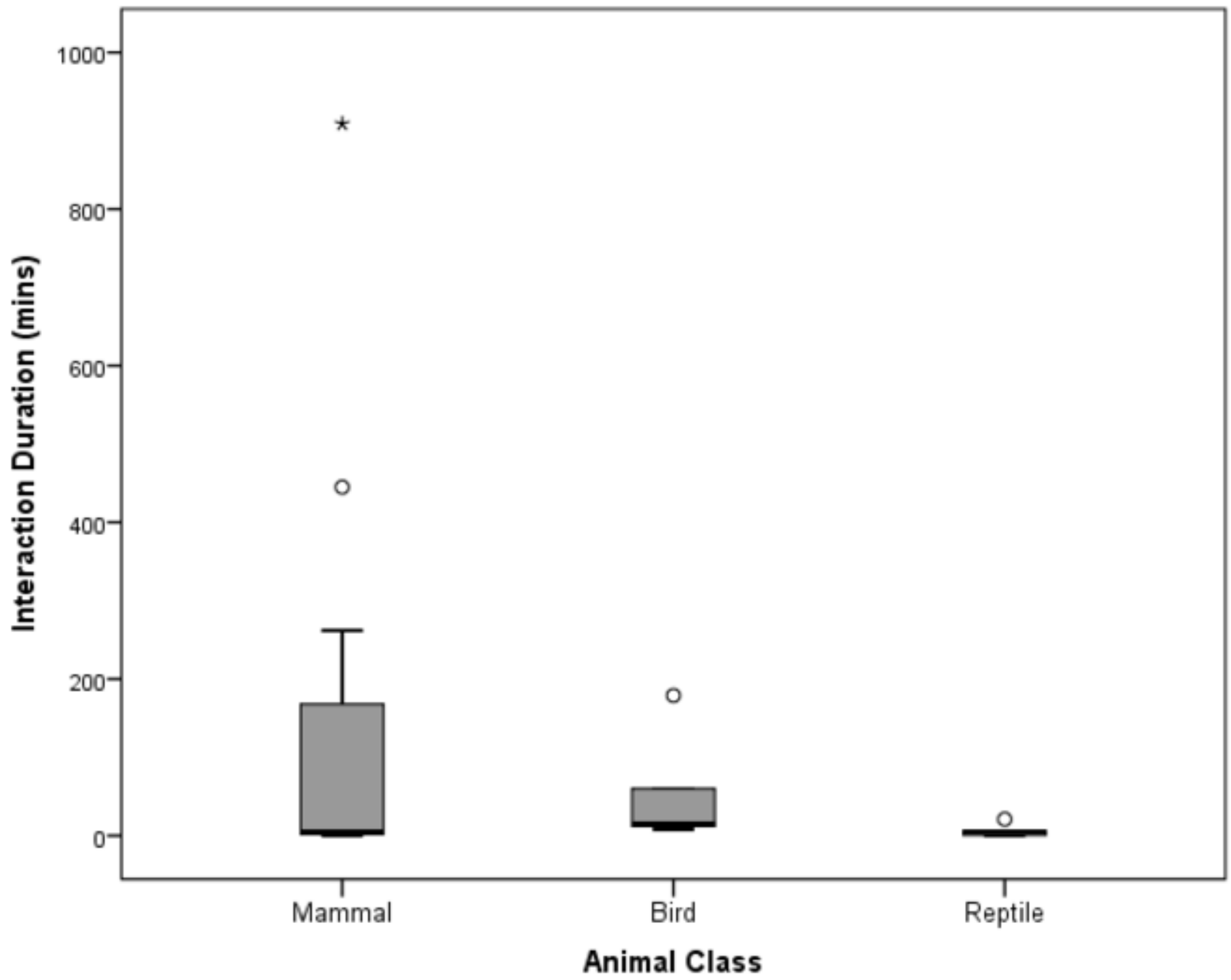

Animal Class 
Figure 4

Click here to download high resolution image

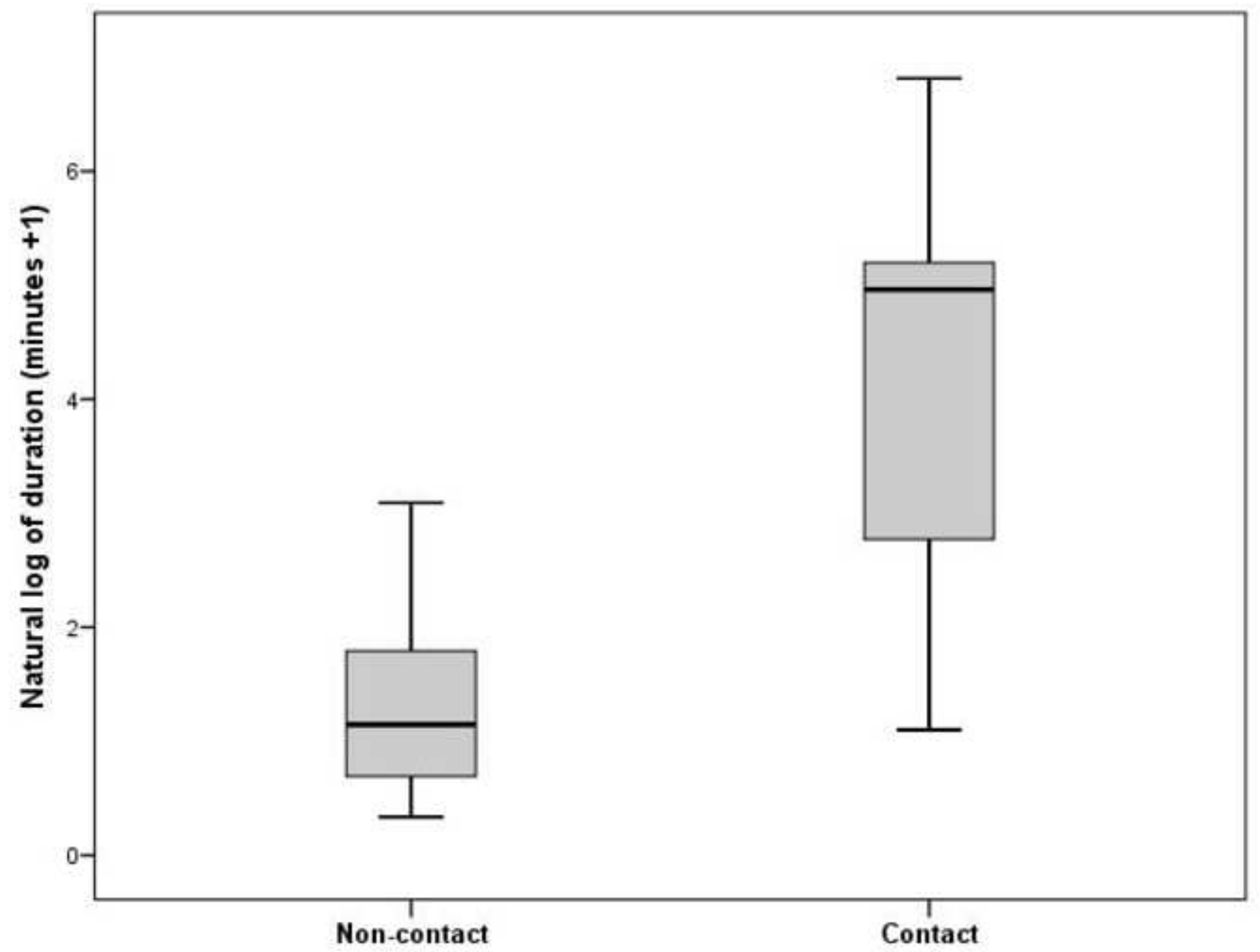




\begin{tabular}{|c|c|c|c|c|c|c|c|c|c|c|}
\hline Interaction & Date & Species & \multicolumn{3}{|c|}{ Noncontact } & \multicolumn{4}{|c|}{ Contact } & Source \\
\hline 2 & $24 / 12 / 1982$ & Owl & & & & $\bullet$ & & $\bullet$ & $\bullet$ & Sugiyama 1989 \\
\hline 3 & $22 / 01 / 1983$ & Pangolin & & & & $\bullet$ & & $\bullet$ & $\bullet$ & Sugiyama 1989 \\
\hline 5 & $23 / 01 / 1986$ & Pangolin & & & & $\bullet$ & & $\bullet$ & & Sugiyama 1989 \\
\hline 6 & 08/01/1995 & Hyrax & & & $\bullet$ & & & & & Hirata et al. 2001 \\
\hline 7 & 02/09/1997 & Squirrel & $\bullet$ & & & & & & & $\mathrm{TH}$ \\
\hline 8 & $18 / 09 / 1997$ & Pangolin & & & & $\bullet$ & $\bullet$ & $\bullet$ & $\bullet$ & $\mathrm{TH}$ \\
\hline 12 & $\mathrm{U} / \mathrm{C}$ & Duiker & & & & $\bullet$ & & $\bullet$ & & TM \& Sakura, Hirata et al. 2001 \\
\hline 13 & $07 / 07 / 2001$ & Dog & & $\bullet$ & & & & & & $\mathrm{TH}$ \\
\hline 14 & $19 / 07 / 2001$ & Dog & & $\bullet$ & & & & & & $\mathrm{TH}$ \\
\hline 15 & $18 / 12 / 2003$ & Pangolin & & & & $\bullet$ & & $\bullet$ & $\bullet$ & Biro \& Sousa, Hockings et al.2007 \\
\hline 16 & $19 / 06 / 2004$ & Viper & & $\bullet$ & & & & & & $\mathrm{KH}$ \\
\hline 17 & $01 / 09 / 2004$ & Fledgling & & & & $\bullet$ & $\bullet$ & $\bullet$ & & $\mathrm{KH}$ \\
\hline 18 & $18 / 03 / 2005$ & Mouse & & & & - & & $\bullet$ & $\bullet$ & $\mathrm{KH}$ \\
\hline 19 & $08 / 04 / 2005$ & Viper & & $\bullet$ & & & & & & $\mathrm{KH}$ \\
\hline 25 & $07 / 04 / 2006$ & Dog & $\bullet$ & & $\bullet$ & & & & & SC \\
\hline 26 & $27 / 08 / 2006$ & Fledgling & & & & $\bullet$ & & $\bullet$ & $\bullet$ & $\mathrm{TH}$ \\
\hline 27 & $04 / 10 / 2008$ & Potto & & & & $\bullet$ & $\bullet$ & $\bullet$ & $\bullet$ & $\mathrm{KH}$ \\
\hline 28 & $14 / 10 / 2008$ & Duiker & $\bullet$ & & & & & & & $\mathrm{TH}$ \\
\hline 29 & $01 / 11 / 2008$ & Viper & & $\bullet$ & & & & & & $\mathrm{KH}$ \\
\hline 30 & $01 / 11 / 2008$ & Snake & & $\bullet$ & & & & & & $\mathrm{KH}$ \\
\hline 31 & $21 / 02 / 2009$ & Owl & & & & $\bullet$ & $\bullet$ & $\bullet$ & & SC \\
\hline 32 & $22 / 10 / 2009$ & Owl $\left.\right|^{\mathrm{a}}$ & & & & $\bullet$ & & $\bullet$ & & Yamanashi, Carvalho et al. 2010 \\
\hline
\end{tabular}

Table 1. Interaction sessions between chimpanzees and other animals (for species names, see Table 2) listed by date, including interaction type (dots indicate presence of interaction) and source of information (initials of authors or published source of information). ${ }^{\text {a }}$ During session 32, playful behaviour was not confirmed, due to lack of details of the observation. 


\begin{tabular}{|c|c|c|c|c|c|c|}
\hline Class & Order & Common name & Species & Activity pattern & Abundance rating & No. interactions \\
\hline \multirow[t]{17}{*}{ Mammal } & Artiodactyla & Red-flanked duiker & Cephalophus rufilatus & Nocturnal/diurnal & Occasional & 1 \\
\hline & & Blue duiker & Philantomba monticola & Nocturnal & Occasional & 1 \\
\hline & & Bongo & Tragelaphus eurycerus & Nocturnal & Rare & 0 \\
\hline & & Bushbuck & Tragelaphus scriptus & Nocturnal/diurnal & Occasional & 0 \\
\hline & Carnivora & Common Kusimanse & Crossarchus obscurus & Diurnal & Occasional & 0 \\
\hline & & West African genet & Genetta pardina & Nocturnal & Rare & 0 \\
\hline & & Slender Mongoose & Herpestes sanguinea & Diurnal & Frequent & 0 \\
\hline & Hyracoidea & Western tree hyrax & Dendrohyrax dorsalis & Nocturnal & Rare & 2 \\
\hline & Insectivora & African pygmy hedgehog & Atelerix albiventris & Nocturnal & Rare & 0 \\
\hline & Pholidota & African tree pangolin & Manis tricuspis & Nocturnal & Rare & 7 \\
\hline & Primata & Lesser bush baby & Galago senegalensis & Nocturnal & Occasional & 0 \\
\hline & & Potto & Perodicticus potto & Nocturnal & Rare & 1 \\
\hline & Rodentia & African porcupine & Atherurus africanus & Nocturnal & Rare & 0 \\
\hline & & Gambian rat & Cricetomys gambianus & Nocturnal & Rare & 0 \\
\hline & & Greater cane rat & Thryonomys swinderianus & Nocturnal & Rare & 0 \\
\hline & & African ground squirrel & Xerus erythropus & Diurnal & Very frequent & 3 \\
\hline & & Mouse & Unidentified spp. & -------------- & ------------ & 1 \\
\hline Bird & Strigiformes & African wood-owl & Ciccaba woodfordii & Nocturnal & Occasional & 3 \\
\hline Reptile & Squamata & Gaboon viper & Bitis gabonica & Nocturnal & Occasional/Frequent & 5 \\
\hline
\end{tabular}

Table 2. Class, order, species and common names of wild animals present at Bossou, including their predominant activity pattern (diurnal or nocturnal, excluding crepuscular) and median rated abundance category. The species of mouse was not confirmed and thus not rated in questionnaires. 


\begin{tabular}{|c|c|c|c|}
\hline \multicolumn{2}{|c|}{ Class and common name } & \multirow{2}{*}{$\begin{array}{c}\text { Non-contact } \\
4\end{array}$} & \multirow{2}{*}{$\begin{array}{c}\text { Contact } \\
0\end{array}$} \\
\hline Mammal $(n=21)$ & Dog* & & \\
\hline & Duiker & 1 & 1 \\
\hline & Goat $^{*}$ & 1 & 0 \\
\hline & Hyrax & 1 & 1 \\
\hline & Mouse & 0 & 1 \\
\hline & Pangolin & 0 & 7 \\
\hline & Potto & 0 & 1 \\
\hline & Squirrel & 3 & 0 \\
\hline & & $10(48 \%)$ & $11(52 \%)$ \\
\hline \multirow[t]{3}{*}{ Bird $(n=5)$} & Unidentified fledgling & & 2 \\
\hline & Owl & & 3 \\
\hline & & & $5(100 \%)$ \\
\hline \multirow[t]{3}{*}{ Reptile $(n=6)$} & Unidentified snake & 1 & \\
\hline & Viper & 5 & \\
\hline & & $6(100 \%)$ & \\
\hline
\end{tabular}

Table 3. Frequency $(\mathrm{N}=32)$ of contact and noncontact interactions between chimpanzees and other species (domesticated species highlighted with *). Duiker species are combined. 


\begin{tabular}{|c|c|c|c|c|c|c|c|c|c|c|c|c|c|c|c|c|c|}
\hline \multirow[b]{2}{*}{$\begin{array}{c}\text { Interaction } \\
\text { no. }\end{array}$} & \multirow[b]{2}{*}{ Species } & \multirow[b]{2}{*}{ Individual } & \multirow[b]{2}{*}{ Age-Sex } & \multicolumn{14}{|c|}{ Behavioural Pattern } \\
\hline & & & & Nest & Groom & Drop & Dis & Pluck & Rub & Tap & Slap & Press & Drum & Probe & Swing & Bite & Carry \\
\hline 2 & Owl & Fo & $6 \mathrm{~F}$ & & & & & - & & & & & & & & & \\
\hline 3 & Pangolin & $\mathrm{Ki}$ & $7 \mathrm{~F}$ & - & & & & & & & & & & & & & \\
\hline 3 & Pangolin & SK & $20 \mathrm{M}$ & & & & & & & • & - & & & & & - & \\
\hline 8 & Pangolin & $\mathrm{Ft}$ & $6 \mathrm{~F}$ & & & $\bullet$ & & & & & & & & & & & \\
\hline 8 & Pangolin & Vv & $4 \mathrm{~F}$ & $\bullet$ & & & & & & & & & $\bullet$ & & & & \\
\hline 9 & Hyrax & Vv & $8 \mathrm{~F}$ & $\bullet$ & $\bullet$ & & & $\bullet$ & & $\bullet$ & & $\bullet$ & & - & & & \\
\hline 9 & Hyrax & $\mathrm{YL}$ & $8 \mathrm{M}$ & & & $\bullet$ & & & & & - & & & & $\bullet$ & & \\
\hline 17 & Fledgling & $\mathrm{PE}$ & $7 \mathrm{M}$ & & & & & & & & & & & & & & $\bullet$ \\
\hline 27 & Potto & $\mathrm{JJ}$ & $11 \mathrm{M}$ & & & & & & & $\bullet$ & $\bullet$ & & $\bullet$ & & & & \\
\hline 31 & Owl & $\mathrm{PE}$ & $11 \mathrm{M}$ & $\bullet$ & & & $\bullet$ & & $\bullet$ & & & $\bullet$ & & $\bullet$ & & & \\
\hline 32 & Owl & PE & $11 \mathrm{M}$ & & $\bullet$ & & & $\bullet$ & & & & & & & & & \\
\hline
\end{tabular}

Table 4. Accompanying behavioural patterns exhibited during contact interactions, including interaction number, species, individual actor, age (years) and sex (F: female, M: male) of actor, and behaviour. Nest: make nest and toy with animal in nest; Groom: groom the animal; Drop: routinely drop and retrieve the animal; Dis: dismember the animal; Pluck: pluck hairs or feathers without damaging skin; Rub: rub animal on genitals; Tap: hit or tap with heel of foot or hand; Slap: slap animal on hard substrate; Press: apply consistent pressure with hand or foot; Drum: rhythmically beat animal with hands; Probe: Inspect and probe animal with fingers; Swing: swing animal in air; Bite: Investigative bite without consumption; Carry: carry animal on back whilst holding it. 
Author Supplementary Material
Click here to download Author Supplementary Material: Hockings.wmv

(

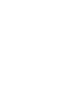

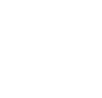

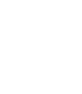

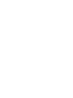
.

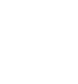

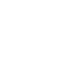
.

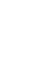

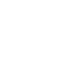
(1) (1) (1) (1) (1) (1) (1) . 列

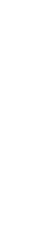

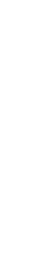
更 . . .

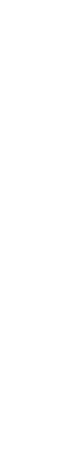

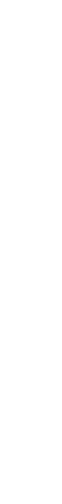
. 列 .

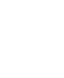

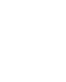

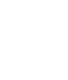

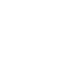

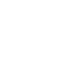

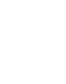

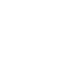

